\title{
Blue to Yellow Photoluminescence Emission and Photocatalytic Activity of Nitrogen Doping in $\mathrm{TiO}_{2}$ Powders
}

\author{
Gabriela Byzynski, ${ }^{1,2}$ Caue Ribeiro, ${ }^{2}$ and Elson Longo ${ }^{1}$ \\ ${ }^{1}$ Chemistry Department, Paulista State University, UNESP, Prof. Francisco Degni Street 55, Quitandinha, \\ 14800-060 Araraquara, SP, Brazil \\ ${ }^{2}$ Embrapa Instrumentação, Rua XV de Novembro 1452, 13560-970 São Carlos, SP, Brazil
}

Correspondence should be addressed to Gabriela Byzynski; gabi.byzynski@gmail.com

Received 24 February 2015; Revised 17 April 2015; Accepted 9 June 2015

Academic Editor: Mohammad Muneer

Copyright (C) 2015 Gabriela Byzynski et al. This is an open access article distributed under the Creative Commons Attribution License, which permits unrestricted use, distribution, and reproduction in any medium, provided the original work is properly cited.

\begin{abstract}
The defects caused by doping are important for understanding the increased photocatalytic activities of $\mathrm{TiO}_{2}: \mathrm{N}$ in organic reactions and in the evaluation of $\mathrm{OH}$ radical production after doping. $\mathrm{TiO}_{2}: \mathrm{N}$ was therefore synthesized using a modified polymeric method and $\mathrm{N}$ doping was performed by calcination with urea. The resulting powders were characterized using field emission scanning electron microscopy, X-ray diffraction, diffuse reflectance spectroscopy, Raman spectroscopy, Fourier transformation infrared spectroscopy, and photoluminescence emission spectroscopy (PL). N doping did not alter the morphology of the nanoparticles, and the anatase phase predominated, with the retention of the rutile phase. The band gap values, superficial areas, and crystallite sizes of the powders decreased after doping. The PL results showed an additional energy level in the $\mathrm{TiO}_{2}: \mathrm{N}$ band gap structure as a result of $\mathrm{TiO}_{2}$ lattice defects caused by doping. At low $\mathrm{N}$ contents, the powders showed continuous emissions from the blue region to the yellow region and a high $\mathrm{N}$ content shifted the PL emissions to the red region. These results suggest that the use of these powders could increase the efficiencies of solar cells and water-splitting processes. The photocatalytic activity of the powders under UVC illumination was confirmed for different organic dye molecules. The $\mathrm{OH}$ radical production did not change extensively after doping, as shown by experiments with terephthalic acid, and higher photocatalytic efficiencies in Rhodamine-B degradation under UVC illumination were achieved using the doped samples.
\end{abstract}

\section{Introduction}

Hydroxyl radicals produced by photon excitation with photocatalysts are widely used in the remediation of organic pollutants and similar processes. This heterogeneous catalytic process, also known as the advanced oxidative process, is based on the incident photon at the photocatalyst surface, generally $\mathrm{TiO}_{2}, \mathrm{ZnO}, \mathrm{CdS}$, or $\mathrm{SrTiO}_{3}$, producing charge separation if the photon energy is above the semiconductor band gap. Reductive and oxidant sites are then created to complete this process [1]. $\mathrm{TiO}_{2}$ is a good photocatalyst for these purposes and has been extensively studied [2-9].

$\mathrm{TiO}_{2}$ has a wide band gap $(3.2 \mathrm{eV})$, which limits its photoactivity to the ultraviolet (UV) region. Doping extends the wavelength absorption of $\mathrm{TiO}_{2}$, and one of the best options for achieving this goal is replacing lattice $\mathrm{O}$ with anionic dopants such as $\mathrm{N}[2,3,6]$. Doping induces energy levels creation within the band gap, which increases the electron-hole pair yield under irradiation with visible light, because the delocalized $\mathrm{s} / \mathrm{p}$ states at the band gap edges improve the charge mobility. The increased charge mobility increases the photocatalytic activity of $\mathrm{TiO}_{2}$.

Defects caused by doping, such as $\mathrm{O}$ vacancies $\left(\mathrm{V}_{\mathrm{O}}\right)$, result in color centers and are closely related to the visible light activity of $\mathrm{TiO}_{2}$. Theoretical studies have shown that the visible light performance of doped $\mathrm{TiO}_{2}$ can be partly attributed to defects created during doping [10]. It is important to correlate the defects caused by doping with the increase in the photocatalytic activity. The aim of this study was to investigate the role of such defects using photoluminescence (PL) spectroscopy over a wide visible light wavelength range. It is also important to correlate the creation 
of defects by doping with the photocatalytic activity and $\mathrm{OH}$ radical production and identify the changes caused by $\mathrm{N}$ doping.

\section{Methods}

2.1. Synthesis of $\mathrm{TiO}_{2}: \mathrm{N}$. In this study, we attempted to incorporate $\mathrm{N}$ atoms easily into $\mathrm{TiO}_{2}$, in higher amounts than those generally used [2-9]. $\mathrm{Ti}^{4+}$ resins were prepared by a polymeric precursor method, as described in our previous work [7], by dissolving titanium tetraisopropoxide (Aldrich) in an aqueous solution of citric acid (Merck) at $75^{\circ} \mathrm{C}$ in a molar ratio of $1: 3$. The titanium citrate obtained was polymerized by adding ethylene glycol (Merck) in a $1: 1$ molar ratio. The doped samples were designed with initial $\mathrm{N}$ contents: SAM $02=1 \mathrm{wt} \%$ of $\mathrm{N}$ (with respect to $\mathrm{TiO}_{2}$ ), SAM $03=3 \mathrm{wt} \%$ of $\mathrm{N}$. SAM 01 is the original $\mathrm{TiO}_{2}$ sample.

\subsection{Powder Characterization. The $\mathrm{TiO}_{2}: \mathrm{N}$ nanoparticles} were characterized by X-ray diffraction (XRD) (Shimadzu XDR 6000), using $\mathrm{Cu} \mathrm{K} \alpha$ radiation $(\lambda=0.154 \mathrm{~nm})$, in the $2 \theta$ range $10-80^{\circ}$, at a scanning rate of $2^{\circ} \mathrm{min}^{-1}$ in order to do the structural characterization of $\mathrm{TiO}_{2}: \mathrm{N}$ nanoparticles. The crystallite sizes of the $\mathrm{N}$-doped $\mathrm{TiO}_{2}$ nanoparticles were determined using the Scherrer formula, from the broadening of at least three different peaks in the XRD pattern [11]; the surface areas (S.A.) were determined by $\mathrm{N}_{2}$ physisorption (ASAP 2000 adsorption analyzer), using the BrunauerEmmett-Teller (BET) method, in a ASAP 2000 adsorption analyzer. The Raman spectra were collected (Horiba Jobin Yvon model HR550 with a CCD detector $\left(-70^{\circ} \mathrm{C}\right)$ ) using the $514 \mathrm{~nm}$ line of a $17 \mathrm{~mW}$ laser; 200 scans were used for each measurement. Fourier transform infrared (FTIR) spectra were also performed (Perkin Elmer FTIR spectrometer 1000 model) for all samples. The size and morphology of the samples were characterized by field emission scanning electron microscopy (FESEM) (FEI/Inspect model F50).

Diffuse reflectance UV-visible (UV-vis) spectra were obtained using a UV-vis-near infrared Cary 5G spectrophotometer. The substrate spectrum was taken as the baseline and was recorded prior to each measurement. UV-vis spectroscopy was performed in diffuse reflectance mode $(R)$ and the spectra were corrected using the Kubelka-Munk model [7]. The band gap values $\left(E_{g}\right)$ of the samples were determined using the Tauc equation [12]:

$$
(\alpha h v)=A_{i}\left(h v-E_{g}\right)^{n}
$$

where $\alpha$ is the absorption coefficient $\left(\mathrm{cm}^{-1}\right), h v$ is the photon energy $(\mathrm{eV})$, and $A_{i}$ is a constant. The $n$ value depends on the nature of the electronic transition and is 1 for a direct and 0.5 for an indirect semiconductor with a crystalline structure. The equation is only used for monochromatic irradiation, an infinitely thick sample layer, low sample concentration, a uniform solute distribution, and absence of fluorescence. The Tauc equation can therefore be written as

$$
F(R) h v=A_{i}\left(h v-E_{g}\right)^{2} .
$$

PL studies of solid samples were performed using a fluorescence spectrometer (Perkin Elmer LS 55) with a krypton multiline laser with an excitation wavelength of $350 \mathrm{~nm}$.

Rhodamine- $\mathrm{B}$ (Rhod-B) $\left(\mathrm{C}_{28} \mathrm{H}_{31} \mathrm{ClN}_{2} \mathrm{O}_{3}\right)$ photodegradation experiments were performed under UVC and visible light irradiation; each sample $(2 \mathrm{mg})$ was added to a beaker containing Rhod-B aqueous solution $(20 \mathrm{~mL})$ of concentration $2.5 \mathrm{mg} \mathrm{L}^{-1}$. The solution was stirred constantly with a magnetic stirrer and irradiated with six UVC lamps (TUV Philips, $15 \mathrm{~W}$, maximum intensity at $254 \mathrm{~nm}$ ). Visible light irradiation was performed separately, using six fluorescent lamps (Quality, $15 \mathrm{~W}$, maximum intensity at $440 \mathrm{~nm}$ ). The photocatalytic oxidation of Rhod-B was monitored using UV-vis measurements (Shimadzu-UV-1601 PC spectrophotometer) at various light-exposure times. The same Rhod-B photocatalytic experiments under UVC illumination were conducted for two other dyes, methyl orange $\left(\mathrm{C}_{14} \mathrm{H}_{14} \mathrm{~N}_{3} \mathrm{NaO}_{3} \mathrm{~S}\right)(\mathrm{MO})$ and methylene blue $\left(\mathrm{C}_{16} \mathrm{H}_{18} \mathrm{~N}_{3} \mathrm{SCl}\right)$ (MB). Aqueous solutions $(20 \mathrm{~mL})$ at concentrations of $5.0 \mathrm{mg} \mathrm{L}^{-1}$ for $\mathrm{MO}$ and $2.5 \mathrm{mg} \mathrm{L}^{-1}$ for $\mathrm{MB}$ were used.

The photocatalytic activities of the samples were studied using terephthalic acid (TA) oxidation, as described by Raubach et al. [13]. In this reaction, the organic acid is selectively oxidized to 2-hydroxyterephthalic acid, a fluorescent species, by the action of free radicals in solution; therefore the reaction rate is proportional to the radical concentration in the medium. A TA solution $\left(5 \mathrm{~g} \mathrm{~L}^{-1}\right)$ was prepared by dissolving TA in water. The $\mathrm{TiO}_{2}$ samples ( $2 \mathrm{mg}$ ) were placed in beakers and immersed in TA solution $(20 \mathrm{~mL})$. The fluorescence spectra of 2-hydroxyterephthalic acid were obtained using a Perkin Elmer luminescence spectrometer LS50B [13]. The samples in TA solution were illuminated with UV and visible light. The fluorescence emission spectra (excitation at $315 \mathrm{~nm}$ ) of the solutions were recorded every $15 \mathrm{~min}$ during illumination. A sample without any photocatalyst, that is, only TA solution, was also illuminated with UV and visible light.

\section{Results and Discussion}

Figure 1 presents the FESEM images of SAM 01 (a), SAM 02 (b), and SAM 03 (c), which indicate that the $\mathrm{N}$ doping process did not alter the particle morphology. This would be evident as agglomeration of the spherical nanoparticles, which have an average size of $10-15 \mathrm{~nm}$ in the undoped sample. In Figure 1(c), the nanoparticle crystals cannot be clearly identified, as is possible in Figure 1(a), demonstrating that the $\mathrm{N}$ doping process could promote a reduction in the nanoparticle size. This decrease in size directly modifies the superficial area, generating a greater interaction between the nanoparticles, thus promoting the smoother appearance of nanoparticles in the FESEM images of SAM 02 and SAM 03 than that of the undoped sample, SAM 01.

Figure 2(a) shows XRD data for nanoparticles with different $\mathrm{N}$ contents. The data show that anatase and rutile phases are present in all samples, even at the higher $\mathrm{N}$ content (SAM 03). However, as the $\mathrm{N}$ percentage increases, the anatase phase becomes predominant; that is, the presence of $\mathrm{N}$ causes 


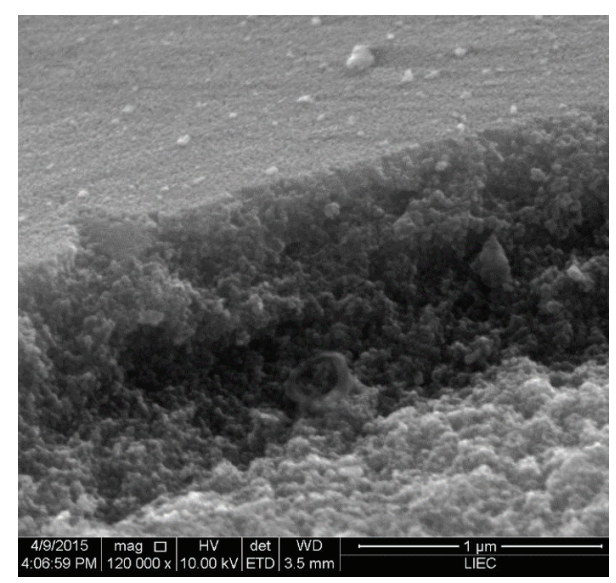

(a)

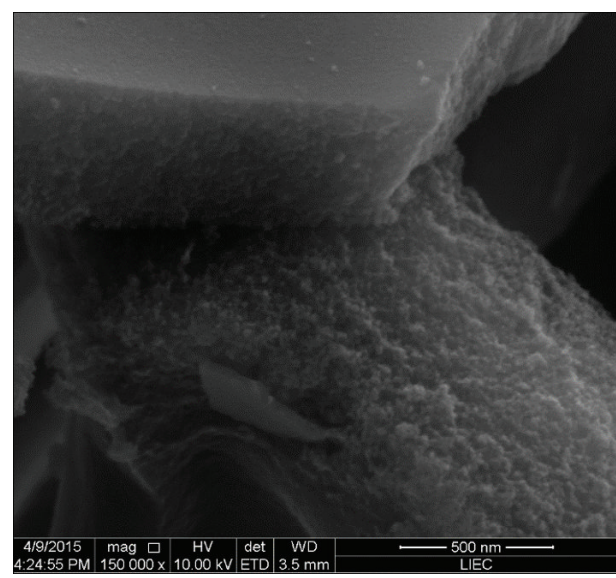

(b)

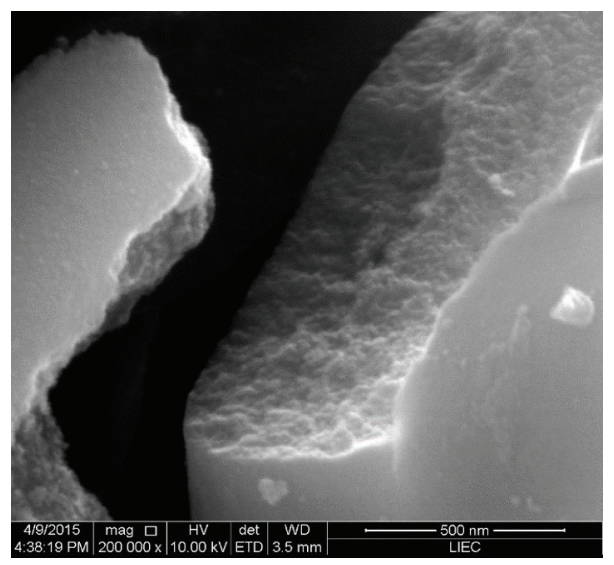

(c)

FIGURE 1: FESEM images of the $\mathrm{TiO}_{2}$ nanoparticles: (a) SAM 01; (b) SAM 02; (c) SAM 03.

the anatase retention effect associated with doping [7]. This result also confirms that the dopant has not altered the anatase and rutile structures; TiN was not identified in either of the samples.

Figure 2(b) shows that the anatase (101) diffraction peaks shift to higher angles for SAM 03. This change could be related to $\mathrm{N}$ substitution of $\mathrm{O}$ sites during doping, although the $\mathrm{N}$ atomic radius is different from the $\mathrm{O}$ atomic radius. When substitution occurs, the doped nanoparticle $\left(\mathrm{TiO}_{2}: \mathrm{N}\right)$ surfaces become more positive because of the electronic distribution of $\mathrm{N}\left([\mathrm{He}] 2 \mathrm{~s}^{2} 2 \mathrm{p}^{3}\right)$, and this can cause structural changes in the lattices of doped nanoparticles.

Figure 2(c) shows the Raman shifts of the synthesized samples, which are in agreement with the spectra reported for titanium oxide predominantly in the anatase phase [7]. The anatase phase is confirmed by the major Raman bands at $160,415,537$, and $659 \mathrm{~cm}^{-1}$. The presence of the rutile phase, especially in SAM 01, is confirmed by Raman bands at 215 and $466 \mathrm{~cm}^{-1}$. As the $\mathrm{N}$ content in doped samples increases, the nanoparticles present a yellow color that could interfere with the Raman band intensity, and the intensity of the anatase phase decreases, as presented in the insert of Figure 2(c). Additionally, the retention of the rutile phase with increasing $\mathrm{N}$ content is confirmed by the Raman band at $466 \mathrm{~cm}^{-1}$.
The $\mathrm{TiO}_{2}: \mathrm{N}$ nanoparticle crystallite sizes were determined, using the Scherrer formula, from the broadening of at least three different peaks in the XRD patterns [11]; the results are listed in Table 1 . The crystallite size decreases with increasing $\mathrm{N}$ content, because anatase retention reduces the boundary mobility [7]. The trend for the S.A. behavior changes is similar to that for crystallite size; that is, as the $\mathrm{N}$ percentage increases, the S.A. decreases. Sample SAM 03 presents a more pronounced decrease in the S.A. compared to the pristine sample (SAM 01), while sample SAM 2 presents an increase in the S.A. These results are in accordance with those in the literature [2-9], which report that doped samples with low $\mathrm{N}$ contents have higher surface areas. The changes in the surface areas indicate that doping changed not only the nanoparticle surfaces but also their sizes.

Figure 3 presents the FTIR spectra of samples synthesized and defines functional group modifications on the nanoparticles surfaces. The synthetized samples show similar spectra with analogous absorption peaks. The absorption peak at $1620-1630 \mathrm{~cm}^{-1}$ is associated with the vibration of adsorbed water molecules bonds and/or surface hydroxyl groups. The absorption peak intensity increases slightly with increasing $\mathrm{N}$ content. It is possible to observe another absorption peak at $3410 \mathrm{~cm}^{-1}$, which is also linked to hydroxyl group vibrations. 


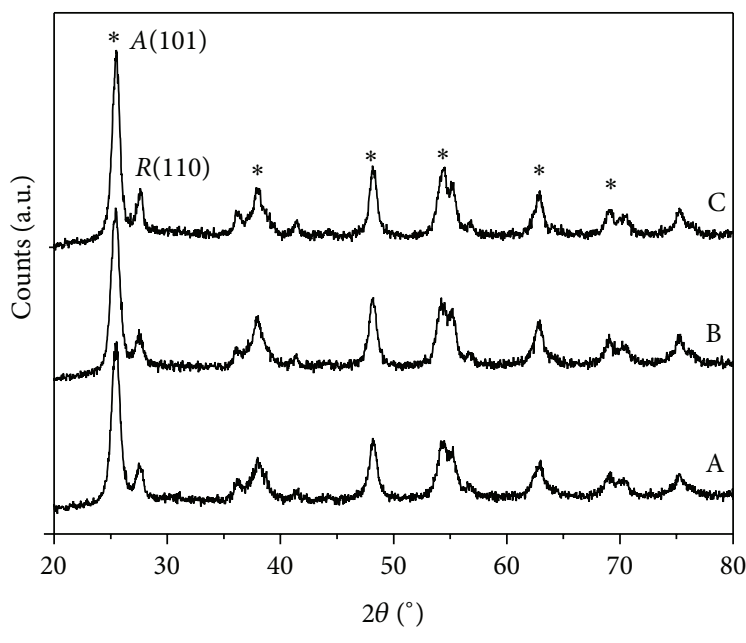

(a)

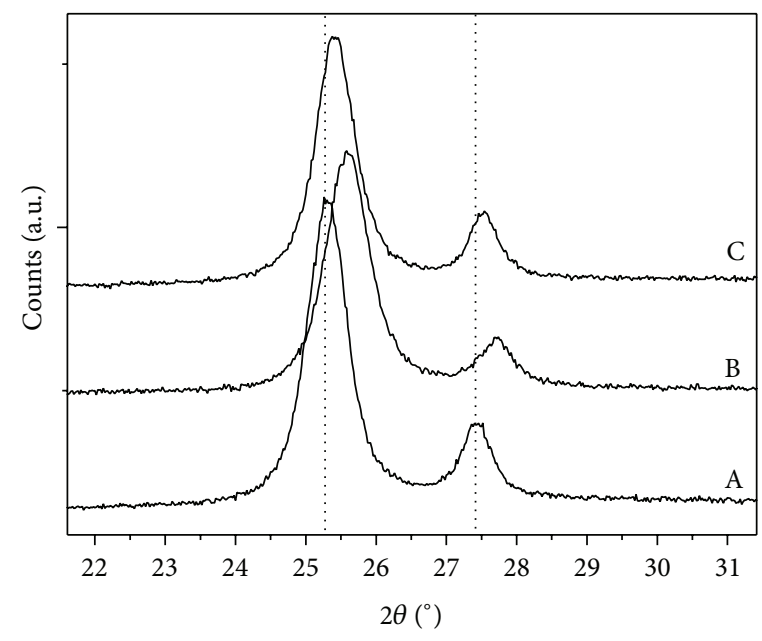

(b)

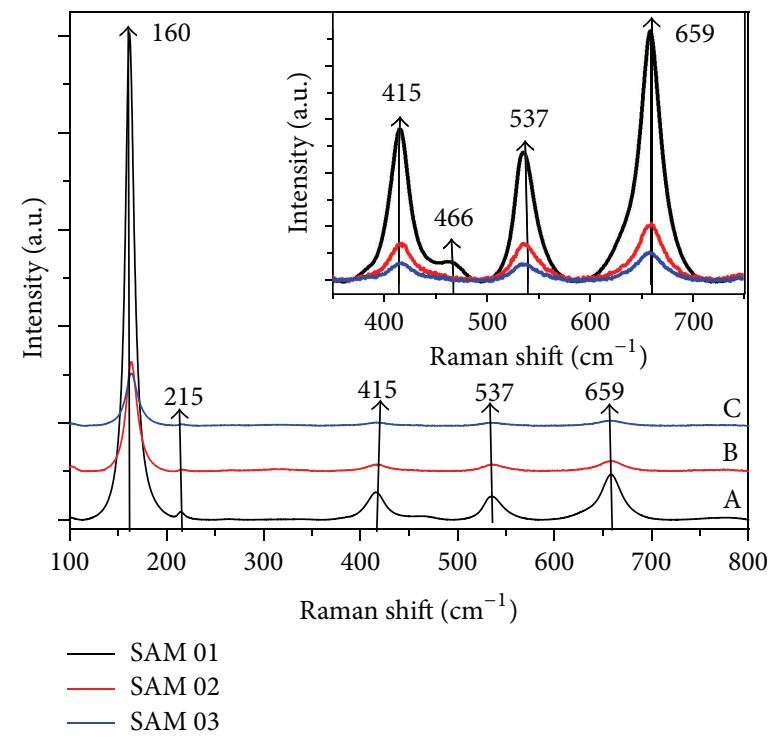

(c)

Figure 2: (a) X-ray diffraction spectra of $\mathrm{TiO}_{2}(A, *)$ and rutile $(R)$ between 20 to $80^{\circ}, 0,02^{\circ} / \mathrm{min}$. (b) X-ray diffraction spectra between 20 and $32^{\circ}$ with the shift of main diffraction peak of $\mathrm{TiO}_{2}$ anatase and rutile. (c) Raman spectra between 100 and $800 \mathrm{~cm}^{-1}$. Insert: Raman spectra between 350 and $7500 \mathrm{~cm}^{-1}$ of (A) SAM 01, (B) SAM 02, and (C) SAM 03.

Its intensity is also elevated for the sample with a higher $\mathrm{N}$ dopant content (SAM 03) compared to that of the pristine $\mathrm{TiO}_{2}$ (SAM 01). The absorption peak at $485 \mathrm{~cm}^{-1}$ is typically attributed to Ti-O and Ti-O-Ti bond vibrations (Figure 3). The absorption peak at $900 \mathrm{~cm}^{-1}$ is linked to peroxide (O$\mathrm{O})$ bond vibrations and clearly increases in intensity as the $\mathrm{N}$ content in samples increases. The presence of $\mathrm{N}-\mathrm{H}$ bond vibrations at $1400 \mathrm{~cm}^{-1}$ could be avoided due to $\mathrm{N}$ atoms located near a $\mathrm{Ti}$ atom in interstitially doped samples or replacing $\mathrm{O}$ atoms in substitutionally doped samples [14].

Figure 4 shows the diffuse reflectance UV-vis spectra of the samples. The absorption behavior clearly changes after doping and with increasing $\mathrm{N}$ content, indicating that $\mathrm{N}$ doping increases interference in the absorption profiles. The absorption behaviors between 400 and $600 \mathrm{~nm}$ in the spectra indicate interenergetic bands between the conduction and valence bands of $\mathrm{TiO}_{2}$ after $\mathrm{N}$ doping. Band gap values are easily obtained from diffuse reflectance spectroscopy measurements using the Tauc function [12] (Figure 4(b)); the values are presented in Table 1 . The band gap value is obtained by plotting the Tauc function as a function of the energy of the exciting light and extrapolating the linear part of the resulting curve to the desired value. Doping changes the band gap value linearly (Table 1 ). Pristine $\mathrm{TiO}_{2}$ has the highest value $(2.93 \mathrm{eV})$ and SAM 03 has the lowest value $(2.85 \mathrm{eV})$. This energy difference $(0.08 \mathrm{~V})$ is in accordance with that reported in the literature $[2,3,6,9]$. It is important to remember that any decrease in the band gap can improve the nanoparticle properties such as visible light photocatalytic activity $[3,7]$, because the band gap is related to the excitation energy 


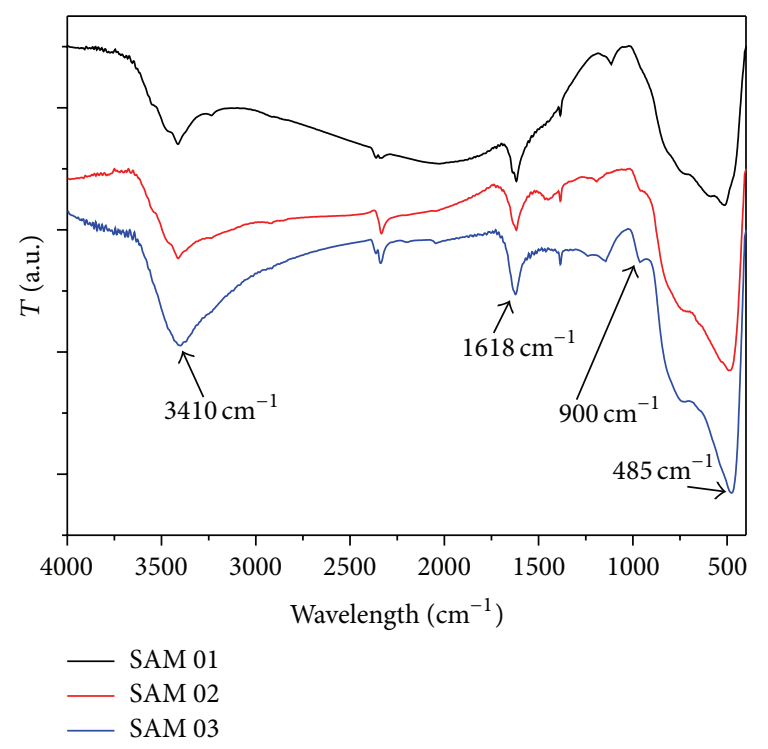

FIGURE 3: FTIR spectra of SAM 01, SAM 02, and SAM 03 samples.

TABLE 1: Crystallite size, superficial area, and band gap values of $\mathrm{TiO}_{2}: \mathrm{N}$ nanoparticles.

\begin{tabular}{lccc}
\hline Samples & $\begin{array}{c}\text { Crystallite size } \\
(\mathrm{nm})\end{array}$ & $\begin{array}{c}\text { Superficial } \\
\text { area }\left(\mathrm{m}^{2} / \mathrm{g}\right)\end{array}$ & $\begin{array}{c}\text { Band gap value } \\
(\mathrm{eV})\end{array}$ \\
\hline SAM 01 & 11 & 44 & 2.93 \\
SAM 02 & 11 & 46 & 2.89 \\
SAM 03 & 10 & 30 & 2.85 \\
\hline
\end{tabular}

of electron transfer between the conduction and valence bands of the semiconductor. Electronic transitions begin at $408 \mathrm{~cm}^{-1}$ for the pristine sample, $409 \mathrm{~cm}^{-1}$ for SAM 02 , and $417 \mathrm{~cm}^{-1}$ for SAM 03. The higher-wavelength absorbance of the doped samples is a good indication of effective doping.

The electronic structure and defects induced by impurities on the oxide surface were investigated using PL spectroscopy; the spectra of SAM 01, SAM 02, and SAM 03 are shown in Figure 5. The emission spectra provide useful information, because electron-hole pairs emit different energies when they decay, including decay related to interlevels, not only band gap decay. When the $\mathrm{TiO}_{2}$ samples were excited at wavelengths lower than $320 \mathrm{~nm}$, the interband recombination peak appeared at around $360 \mathrm{~nm}$ in emission spectrum; another peak appeared at $550 \mathrm{~nm}$, which is ascribed to indirect recombination via $\mathrm{V}_{\mathrm{O}}$. The appearance of other peaks related to the electronic structure and indirect recombination of bulk defects is also possible [15]. Praveen et al. [16] reported similar results for anatase $\mathrm{TiO}_{2}$ nanoparticles excited at $345 \mathrm{~nm}$, with an emission peak at $587 \mathrm{~nm}$, which were attributed to $\mathrm{Ti}^{4+}$ ions near $\mathrm{V}_{\mathrm{O}}$ (intragap surface state). A peak at $431 \mathrm{~nm}(400-450 \mathrm{~nm})$ was observed from a band edge-free excitation, and this surface emission was attributed to an indirect transition, $X_{1 \mathrm{a}}$ to $\Gamma_{1 \mathrm{~b}}$, and was correlated with recombination in shallow trapped surface states.

Figure 5 shows the PL emission spectra between 350 and $850 \mathrm{~nm}$ of the samples excited at $350 \mathrm{~nm}$. A major peak is observed at around $500 \mathrm{~nm}$ for SAM 01 and SAM 02, and another principal peak is observed at around $620 \mathrm{~nm}$ for the other sample. The first peak, at $500 \mathrm{~nm}$, is associated with indirect transitions in the pristine $\mathrm{TiO}_{2}$ sample. As $\mathrm{N}$ is added to the $\mathrm{TiO}_{2}$ crystal, other energy levels are created between the conduction and valence bands, similar to the PL emissions of calcium sulfide behavior synthesized using a microwave-assisted solvothermal method, which shows a blue-shifted emission [16]. The second emission fluorescence peak with a blue emission at around $620 \mathrm{~nm}$ is only observed for the doped samples (SAM 02 and SAM 03) and is associated indirectly with an additional energy level in the band gap; this enables other indirect electronic transitions via radiative recombination between donors charges, associated with $\mathrm{V}_{\mathrm{O}}$, and acceptors, associated with defects [15, 17]. Nonstoichiometric concentrations of $\mathrm{V}_{\mathrm{O}}$ and impurity-related defects in $\mathrm{TiO}_{2}: \mathrm{N}$ help in explaining the results. As impurity atoms are introduced into the $\mathrm{TiO}_{2}$ lattice, the potential energy changes; therefore, the energy level of $\mathrm{V}_{\mathrm{O}}$ changes, resulting in shifts of the emission peaks of the $\mathrm{TiO}_{2}: \mathrm{N}$ samples [17].

The behavior of SAM 02 is clearly different from those of the other samples, and a major peak at around $500 \mathrm{~nm}$ and another peak at around $620 \mathrm{~nm}$ (fluorescence quenching) are observed, indicating transitional behavior between those of the pristine and higher-doped samples. The SAM 02 behavior is attributed to a mixture of $\mathrm{V}_{\mathrm{O}}$ and $\mathrm{N}$ impurities. However, $\mathrm{N}$ impurities occupy the interstitial sites, forming a coulombic shield that transfers the radiation to nearby atoms [17]. This results in a continuous emission from the blue region to the yellow region $(450-650 \mathrm{~nm})$ as a result of radiative recombination between the donors associated with $\mathrm{V}_{\mathrm{O}}$ and acceptors related to the original defects.

After doping, except in the case of SAM 02, the emission spectra of the samples were displaced to the red region; for the pristine sample, emission was observed in the green region of the UV-vis spectrum. For SAM 02 and SAM 03, it is possible to obtain emission across practically the entire visible spectrum, from the blue to green regions, but higher emission was only observed for SAM 02.

The photocatalytic activities of the $\mathrm{TiO}_{2}$ nanoparticles under UVC (maximum at $257 \mathrm{~nm}$ ) and visible (maximum at $550 \mathrm{~nm}$ ) light (Figures 6(a) and 8(a), resp.) were investigated using Rhod-B degradation. Photocatalytic efficiency plots of the $\mathrm{TiO}_{2}$ nanoparticles with different light sources were used to determine the order of the photodegradation reaction. The reaction should be first order with respect to Rhod-B, and the kinetic law can be described as

$$
v=-\frac{d[\text { Rhod }-\mathrm{B}]}{d t}=k[\text { Rhod }-\mathrm{B}][\mathrm{AS}]
$$

and [AS] is the photocatalytic concentration (number of actives sites), which is constant for a given sample; therefore

$$
-\frac{d[\text { Rhod-B }]}{d t}=k^{\prime}[\text { Rhod }-\mathrm{B}]
$$




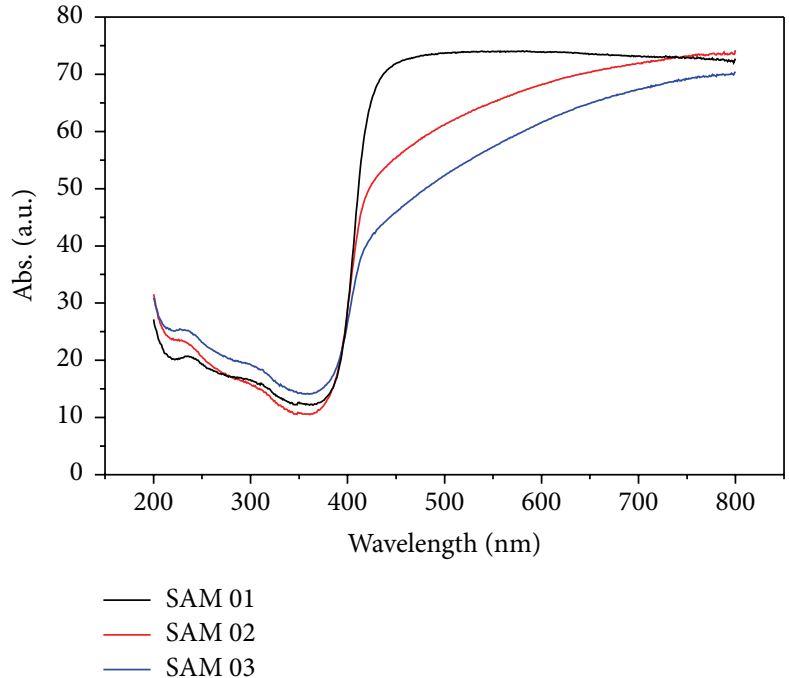

(a)

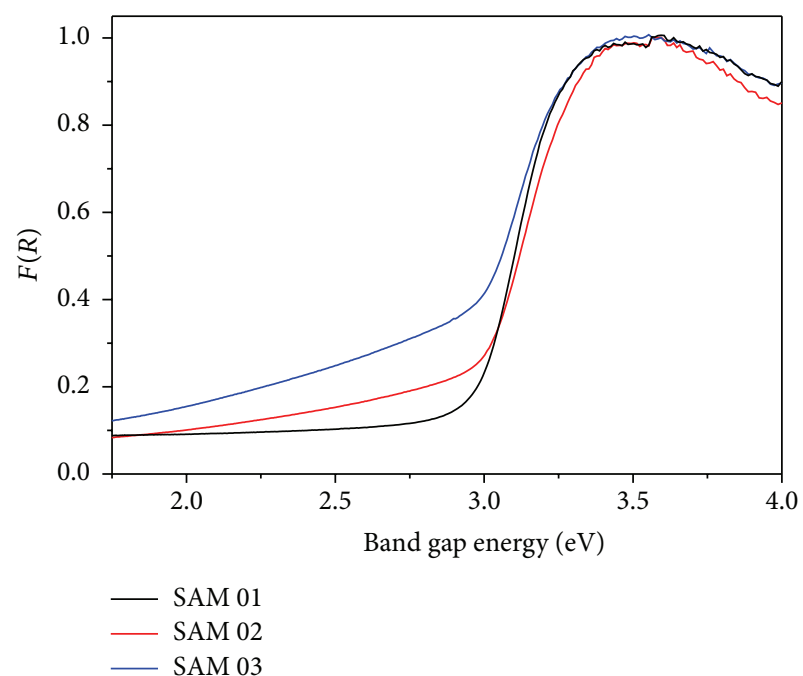

(b)

Figure 4: (a) UV-vis diffuse reflectance spectra of the samples. (b) Tauc equation function versus excitation energy of the samples for band gap determination.

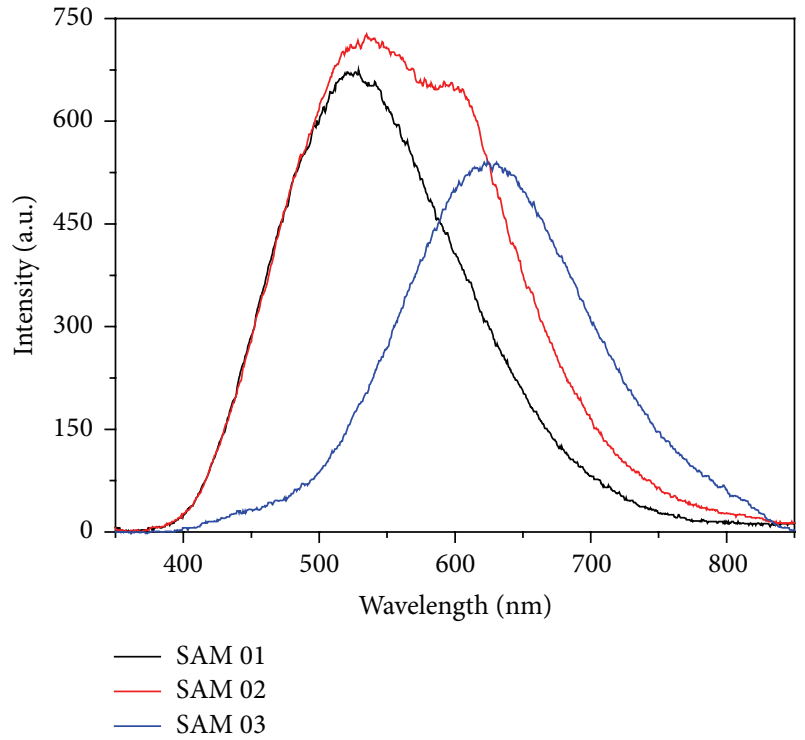

FIGURE 5: Fluorescence emission spectra with excitation in $350 \mathrm{~nm}$ of the samples.

where $k^{\prime}=k[\mathrm{AS}]$; integration gives

$$
-\ln \left(\frac{[\text { Rhod- } \mathrm{B}]}{[\text { Rhod- }]_{0}}\right)=k^{\prime} t
$$

In accordance with (5), if [Rhod-B]/[Rhod-B $]_{0}$ is plotted as a function of $t$, a straight line of slope $k^{\prime}$ is obtained. A comparative study of the kinetic parameters of Rhod-B photodegradation reactions with the different nanoparticle samples was performed.

The rate constant, $k^{\prime}\left(\mathrm{s}^{-1}\right)$, obtained from the curves of Rhod-B photodegradation under UVC and visible light are shown in Figures 6(b) and 8(b), where a column represents the $k^{\prime}$ values. It is important to note that the $k^{\prime}$ values for Rhod-B degradation under visible light are lower than those under UVC light, by an order of $10^{-1}$. Under UVC light, the SAM 02 rate constant is lower than those of SAM 01 and SAM 03; this suggests that the higher $\mathrm{N}$ content significantly increases the UV photocatalytic activity and that $\mathrm{N}$ doping promotes Rhod-B degradation under these conditions. The surface areas are also correlated with the rate constants under UVC illumination. The band gap values are similar to the photocatalytic profiles, but because of the higher energy illuminating the semiconductor surface in the case of UVC illumination, the band gap value is more important for visible light photocatalytic activity.

To confirm the photocatalytic activity of synthesized samples with different dyes, photocatalytic degradation experiments were conducted for $\mathrm{MO}$ and $\mathrm{MB}$, as presented in Figures 7(a) and 7(b), respectively. Under UVC illumination, both dyes underwent photolysis for $2 \mathrm{~h}$, showing increased degradation with the use of these photocatalysts. SAM 01 shows higher photocatalytic activity for dye degradation under UVC illumination, decreasing the initial concentrations $\left(C_{0}\right)$ of $\mathrm{MO}$ and $\mathrm{MB}$ by $52 \%$ and $87 \%$, respectively, over $2 \mathrm{~h}$. The doped samples show lower photocatalytic activity for dye degradation under UVC illumination compared to the pristine sample but nevertheless demonstrate good photocatalytic activity with both dyes. SAM 02 presents concentration decreases of $23 \%$ for $\mathrm{MO}$ and $62 \%$ for $\mathrm{MB}$, while SAM 03 presents decreases of $30 \%$ for MO and $55 \%$ for MB. These results show that it is possible to confirm that the photocatalytic activity efficiencies are influenced, principally by the photocatalyst material/composition through doping, and also by the functional groups of molecules. Some molecules could decompose and generate subproducts that interfere with the photocatalytic activity, generally decreasing the photocatalytic efficiency. 


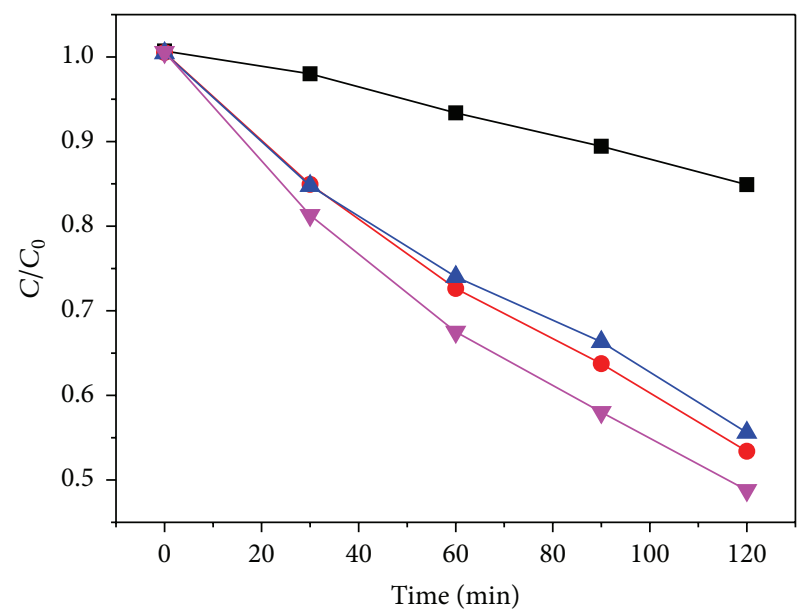

UVC illumination

$\begin{array}{ll}\rightarrow-\text { Rod } & - \text { SAM } 02 \\ - \text { SAM } 01 & \rightarrow \text { SAM } 03\end{array}$

(a)

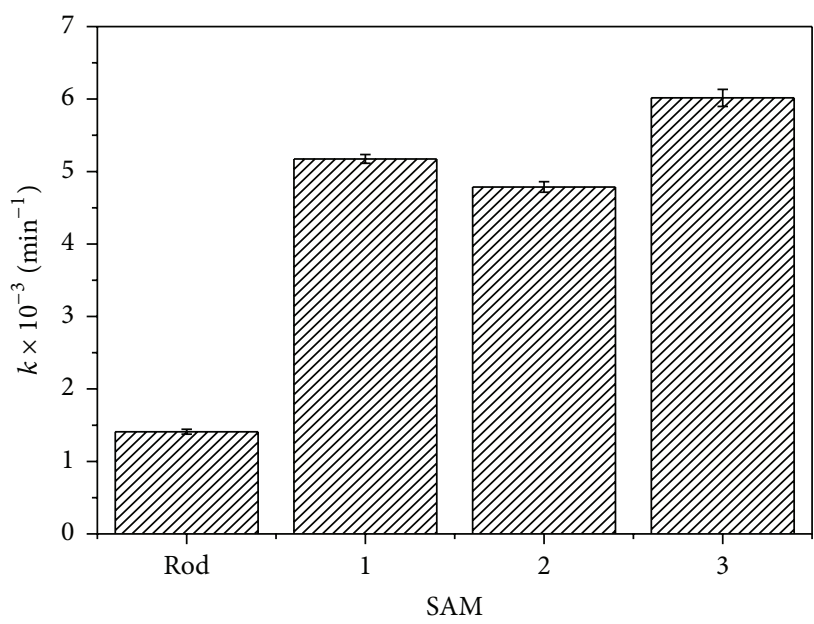

VIIA UVC

(b)

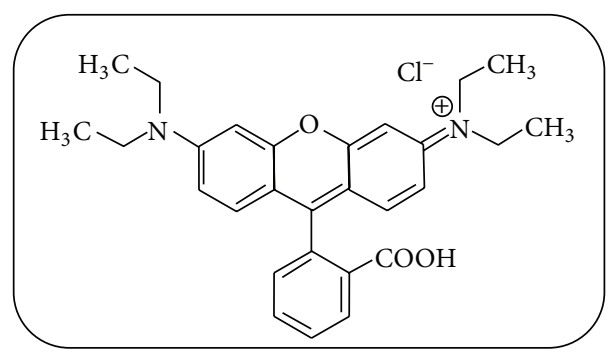

(c)

FIGURE 6: Photodegradation profiles of the Rhod-B solution, using $\mathrm{TiO}_{2}$ nanoparticles with UVC light (a), column graphic of $k$ values under UVC illumination for Rhod-B (b), and Rhodamine-B molecular structure (c).

From Figures 6 and 7, it is possible to verify that the photocatalysis mechanism varies for different dyes. However, it is generally agreed that the primary reactions responsible for the photocatalytic effect are the interfacial redox reactions of electrons and holes that are generated when the semiconductor catalyst is exposed to light of sufficient energy. Holes and electrons produced in this illumination process are consequently responsible for the generation of redox species that will be involved in all degradation mechanisms. Aside from the influence of the dye molecules on the photocatalyst mechanism, other factors such as catalyst concentration, light intensity, reaction time, and the $\mathrm{pH}$ of aqueous solution could also influence this process.

The $\mathrm{pH}$ of the aqueous solution is an important factor in $\mathrm{TiO}_{2}$ synthesis, as it significantly affects the size and form of aggregates and could affect the charge on the particles and positions of the conductance and valence bands. In the photocatalytic process, the $\mathrm{pH}$ changes the manner of interaction between organic pollutants and catalysts and, in particular, the extent of adsorption on the photocatalyst surface. An oxide surface is uncharged at the $\mathrm{pH}$ defined as the zero point charge $\left(\mathrm{pH}_{\mathrm{zpc}}\right)$, which for $\mathrm{TiO}_{2}$ is governed by the production method.
In this context, the isoelectric point (iep) is defined as the condition when positive and negative charges are present on the particle surface in equal amounts; consequently, there is only $\mathrm{H}^{+} / \mathrm{OH}^{-}$ion adsorption at the particle surface. In this case, the iep has the same value as $\mathrm{pH}_{\mathrm{zpc}}$. If the $\mathrm{pH}$ of the aqueous solution is higher than the iep, there is a resultant negative charge at the oxide surface, and the adsorption of cations is preferred as cationic electron oxidation donors and acceptors. Conversely, if the $\mathrm{pH}$ is lower than the iep, the oxide surface charge is positive; the adsorption of anions is favored; consequently, more protons than hydroxide groups are generated by an acidic solution. In summary, the charge on the titanium dioxide surface is negative or positive, according to the equilibrium equations given below [18]:

$$
\begin{gathered}
\mathrm{TiOH}+\mathrm{H}^{+} \longrightarrow \mathrm{TiOH}_{2}^{+} \\
\mathrm{TiOH}+\mathrm{OH}^{-} \longrightarrow \mathrm{TiO}^{-}+\mathrm{H}_{2} \mathrm{O}
\end{gathered}
$$

The iep of the synthesized samples are similar to those of $\mathrm{TiO}_{2}: \mathrm{N}$ obtained in previous work [7], and it is possible that SAM 01, SAM 02, and SAM 03 present an oxide surface that is negatively charged in a solution with neutral $\mathrm{pH}$, as the $\mathrm{pH}$ of the three dye solutions is near to the neutral condition (MO: 8.0, MB: 7.0, and Rhod-B: 7.5). 


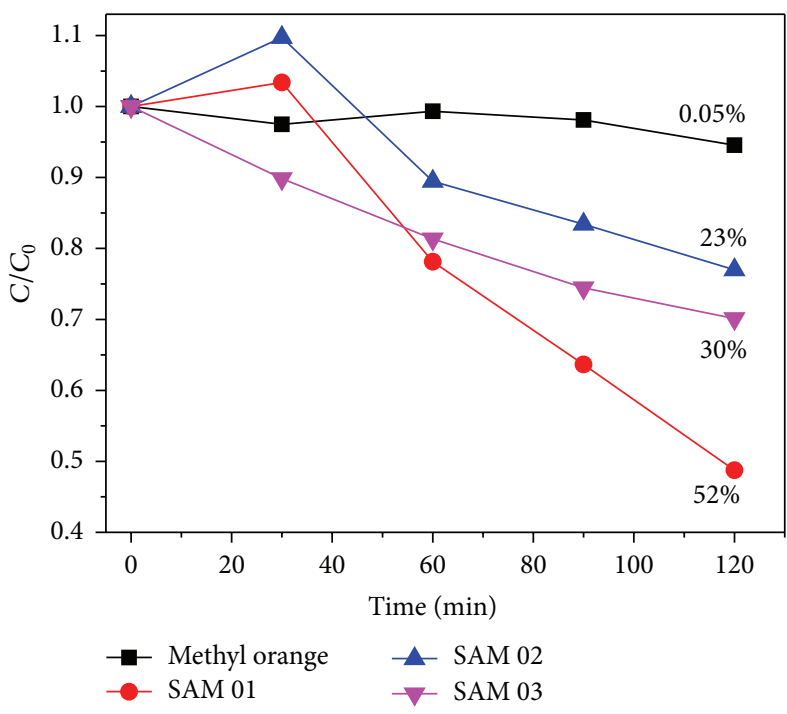

(a)

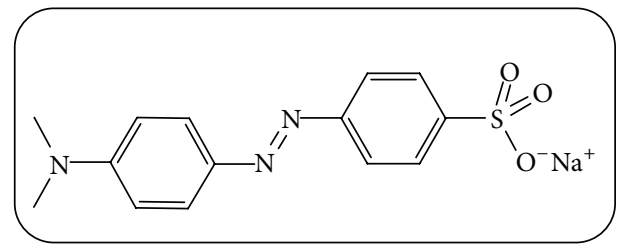

(c)

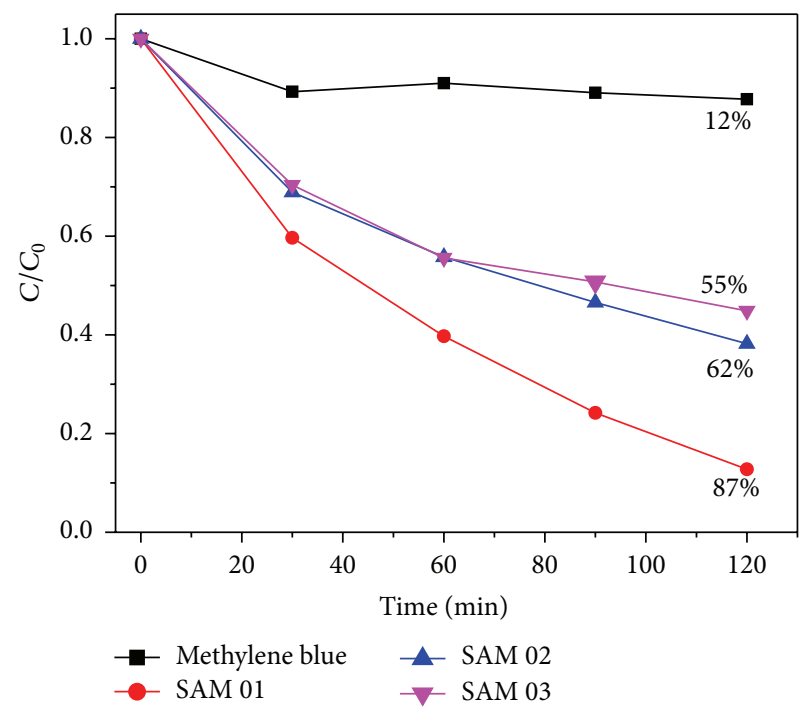

(b)

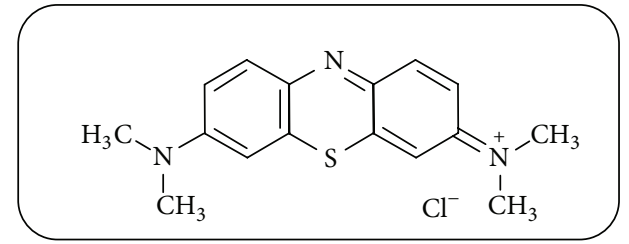

(d)

FIGURE 7: Photodegradation profiles of the methyl orange solution, using $\mathrm{TiO}_{2}$ nanoparticles with UVC light (a) and of the methylene blue solution, using $\mathrm{TiO}_{2}$ nanoparticles with UVC light (b). The numbers indicate the degradation percentage compared to initial concentration used. Methyl orange molecular structure (c) and methylene blue molecular structure (d).

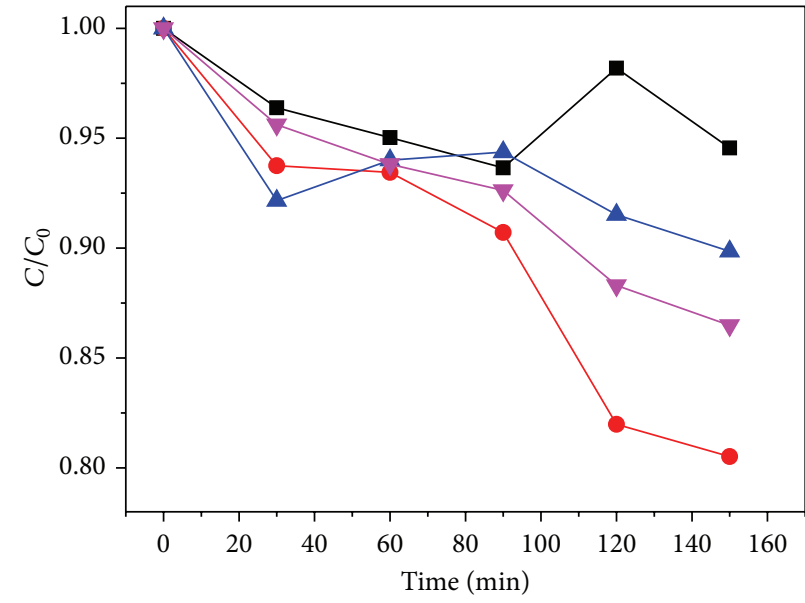

Visible illumination

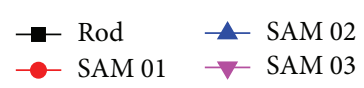

(a)

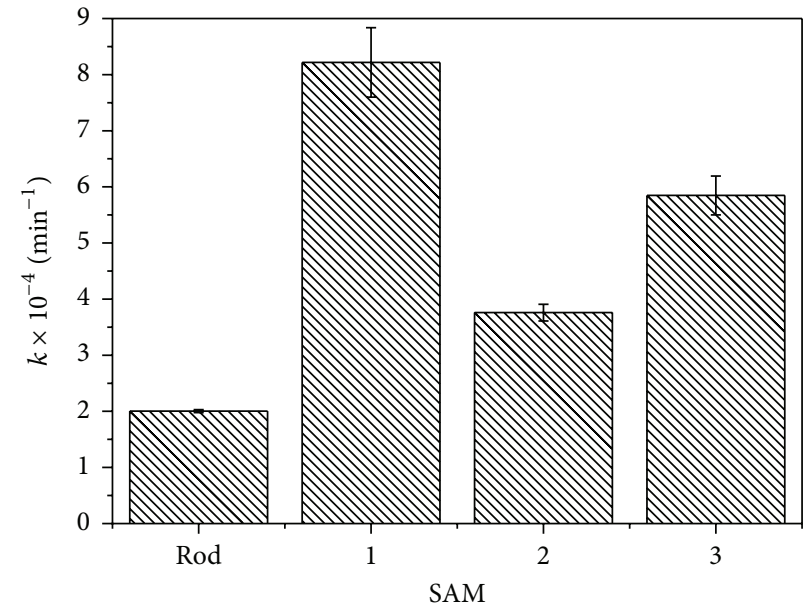

Visible

(b)

Figure 8: Photodegradation profiles of the Rhod-B solution, using $\mathrm{TiO}_{2}$ nanoparticles with visible light (a) and column graphic of $k$ values under visible illumination for Rhod-B (values $10^{-1}$ lower under visible illumination than under UVC illumination) (b). 

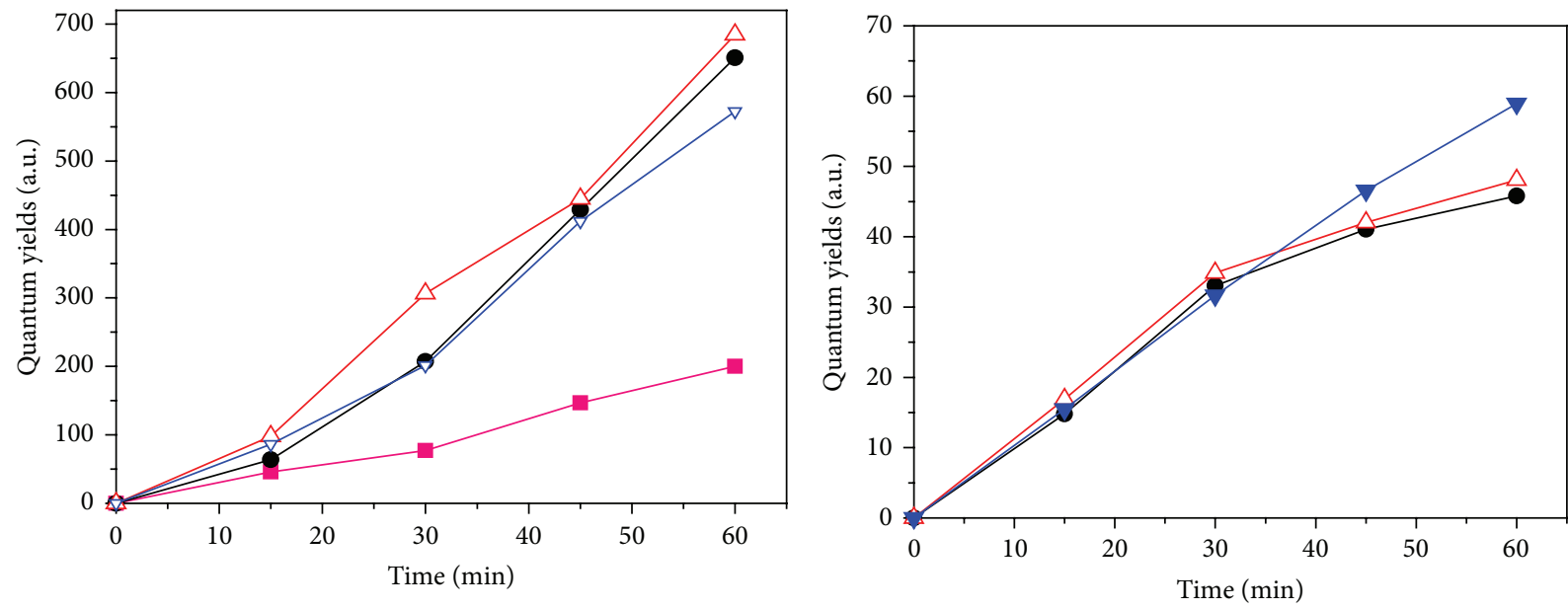

$\begin{array}{ll}\text { UV illumination } & \\ \rightarrow-\text { Blank } & -\checkmark \text { SAM } 02 \\ \rightarrow-\text { SAM } 01 & \rightarrow \text { SAM } 03\end{array}$

Visible illumination

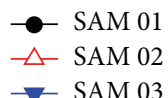

(a)

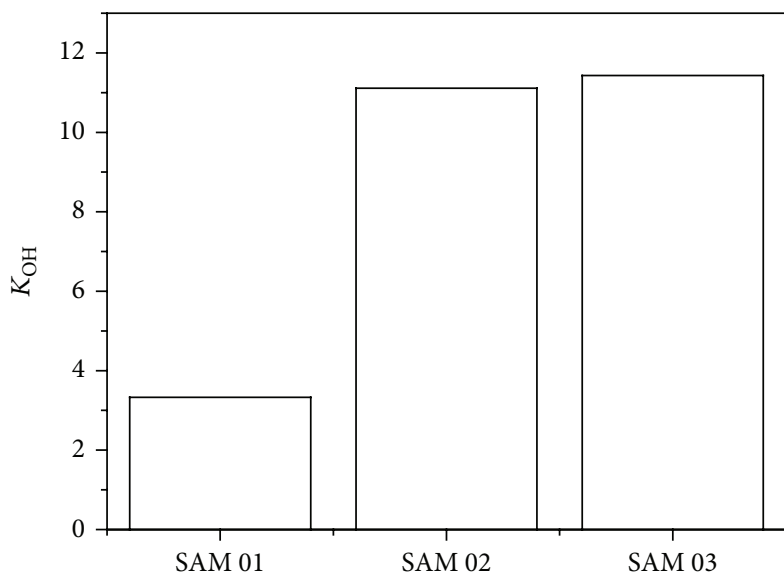

(c)

(b)

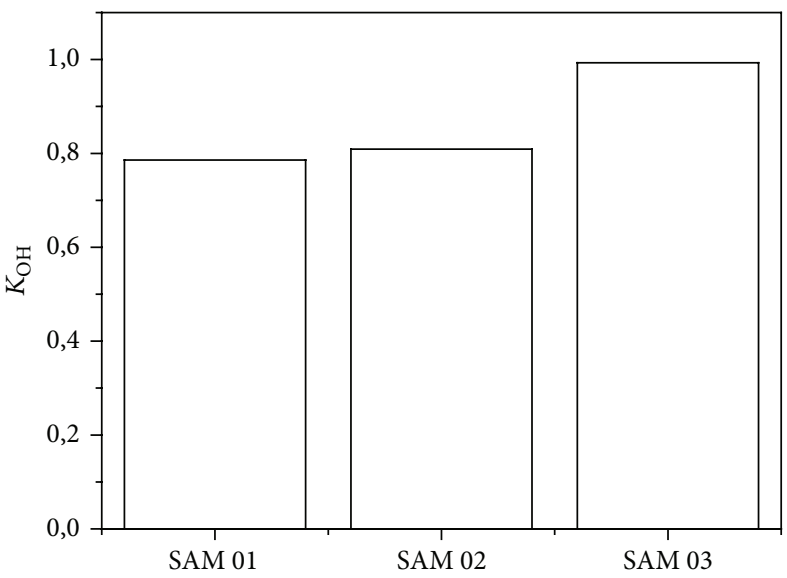

(d)

FIGURE 9: (a) Relation between quantum efficiency of terephthalic acid and hydroxyl radical during UV illumination. (b) Relation between quantum efficiency of terephthalic acid and hydroxyl radical during visible illumination. (c) $K_{\mathrm{OH}}$ values for different samples under UV illumination. (d) $K_{\mathrm{OH}}$ values for different samples under visible illumination.

The ionic species of the dyes are also $\mathrm{pH}$ dependent. The $\mathrm{pka}$ is the $\mathrm{pH}$ at which half of the functional groups are neutralized and half are ionic. At one $\mathrm{pH}$ unit above or below the pka, the functional groups are predominantly in the ionic and neutral form, respectively. The $\mathrm{pH}$ of $\mathrm{MO}(8.0)$, $\mathrm{MB}$ (7.0), and Rhod-B (7.5) solutions are above the pka of $\mathrm{MO}$ (3.39), MB (3.8), and Rhod-B (3.1); consequently, the three dye molecules are present as ionic species in solution.

The variation in the absorption of MO shown in Figure 7(a) is probably due to the insufficient time allowed for equilibration, so that the maximum adsorption was not reached before beginning the photocatalytic process between $\mathrm{MO}$ and the $\mathrm{TiO}_{2}: \mathrm{N}$ nanoparticle surface. Because of the opposite charges on (MO) and the photocatalyst surface, adsorption of $\mathrm{MO}$ over the $\mathrm{TiO}_{2}: \mathrm{N}$ nanoparticle surface occurred and is fundamental for the photocatalysis process.
However, for MO photolysis (Figure 7(a)), it is possible that adsorption time is not the only problem. It is probable that, during the decolorization process, some subproducts form, which have a fast half-life ( $\sim 30 \mathrm{~min})$ and absorb at the same wavelength as MO. Dai et al. [19] reported various subproducts in $\mathrm{MO}$ photocatalytic degradation with $\mathrm{TiO}_{2}$ by identifying them by chromatography (HPLC-MS). One principal subproduct that highly influences the absorption behavior of MO forms from homolytic breaking of a nitrogen-carbon bond in the MO structure, resulting in the substitution of a methyl group by a hydrogen atom.

For methylene blue (MB) shown in Figure 7(b), the absorption behavior is similar to that of Rhod-B under UV illumination; that is, there is no great variation in absorption behavior. This is because, in the photocatalytic process using $\mathrm{TiO}_{2}$, degradation is initiated by the opening of the central 
aromatic ring, resulting in a chromophore molecule that does not interfere with MB absorption [20]. Houas et al. [20] reported that the fastest photocatalytic degradation of $\mathrm{MB}$ with $\mathrm{TiO}_{2}$ occurred at an elevated $\mathrm{pH}$ (9.0); under such conditions, degradation was complete in $40 \mathrm{~min}$. In comparison, complete degradation at a neutral $\mathrm{pH}$ (6.7) required 60 min under UV illumination.

Under visible light, the Rhod-B degradation rate constant profiles have a sinusoidal component (Figures 8(a) and $8(\mathrm{~b}))$. This is probably because $\mathrm{N}$ doping increases the $\mathrm{TiO}_{2}$ nanoparticle photocatalytic activity $[2,3]$. The effect on the activity is clearer for lower $\mathrm{N}$ contents (lower than $2 \%$ molar), and it also depends on the synthetic method. However, the photocatalytic activity of SAM 02 , which has a low $\mathrm{N}$ content, is lower than that of SAM 01. Furthermore, SAM 03, which has a higher $\mathrm{N}$ content, did not improve the Rhod$\mathrm{B}$ degradation efficiency under visible light. The effect of $\mathrm{N}$ doping at this $\mathrm{N}$ content does not promote photocatalytic degradation under visible light; it does so only under UVC illumination. The $\mathrm{N}$ doping diminished the band gap value, probably causing an increase in the recombination rate of photocharge.

The Rhod-B absorption behavior under visible illumination is similar to that previously reported $[7,21]$. The variation in absorption may occur due to one or more of the suggestions previously discussed for $\mathrm{MO}$ and $\mathrm{MB}$, that is, insufficient equilibration time to allow maximum adsorption, solution $\mathrm{pH}$, or even interference by subproducts produced during the photocatalytic process with $\mathrm{TiO}_{2}: \mathrm{N}$ [21]. Li et al. [22] identified the principal products of photocatalytic degradation with $\mathrm{TiO}_{2}$ by HPLC-MS, confirming an interesting difference between UVC and visible illumination: deethylation is reduced under visible light compared to UV irradiation, and consequently the destruction of the chromophore structure predominates.

Several authors have reported better visible light photocatalytic activity for $\mathrm{TiO}_{2}: \mathrm{N}$ particles with lower $\mathrm{N}$ contents [2-7]. However, few authors have investigated the mechanism involved in Rhod-B degradation, that is, the dye-sensitizing mechanism [7]. The degradation mechanism of colored materials involves electron promotion from the dye to the semiconductor bands, inducing an increase in the photocatalytic degradation. However, under visible light, electron and hole photoexcitation in the semiconductor energetic bands can also occur, depending on the band gap value; the main radical responsible for degradation is $\mathrm{OH}^{*}$. To understand the photocatalytic results better, the amount of $\mathrm{OH}$ radicals was determined.

Photocatalytic studies were performed to analyze radical attack to dye for degradation occurs, mainly by $\mathrm{OH}$ radicals, in TA solution under UV and visible light. The fluorescence emission spectra (excitation at $315 \mathrm{~nm}$ ) of the solutions were measured during UV illumination (Figure 9(a)) and visible illumination (Figure 9(b)). As shown in Figures 5(a) and 5(b), a gradual increase in the fluorescence intensity at $425 \mathrm{~nm}$ was observed under both illumination conditions. The behavior was similar for all samples. The fluorescence intensity is related to the fluorescent products formed during photocatalysis, especially to those of the reaction between $\mathrm{OH}$ radicals and TA [22]. The $\mathrm{OH}$ radical formation efficiency can be estimated by comparing the absolute quantum yields for each sample at each measurement time, as shown in Figure 9(a) for UV illumination and Figure 9(b) for visible illumination. The slopes of the sample reaction plots were obtained as described previously for photocatalytic degradation and were correlated with $\mathrm{OH}$ radical formation.

In our model, the ideal catalyst semiconductor $\left(\mathrm{TiO}_{2}\right.$ or $\left.\mathrm{TiO}_{2}: \mathrm{N}\right)$ needs to have some specific features. The most important events occur before the excitation light source reaches the system; the nanoparticle catalysts must be able to generate charges, as shown in (8), because the $\mathrm{TiO}_{2}$ and $\mathrm{TiO}_{2}: \mathrm{N}$ nanoparticles have structural defects (orderdisorder) ascribed to different types of vacancies, that is, $\left[\mathrm{TiO}_{5} \mathrm{~V}_{\mathrm{O}}{ }^{x}\right],\left[\mathrm{TiO}_{5} \mathrm{~V}_{\mathrm{O}}{ }^{\bullet}\right]$, or $\left[\mathrm{TiO}_{5} \mathrm{~V}_{\mathrm{O}}{ }^{\bullet \bullet}\right]$ clusters [19].

Theoretical studies have shown that symmetry breaking (effect of order-disorder) in the structures of various semiconductors is a necessary condition for the presence of intermediary energy levels within the forbidden band gap $[23,24]$. These structural changes are related to shortand medium-range charge polarization, which can be a manifestation of quantum confinement (independent of the particle size). The key point of quantum confinement is the presence of discrete energy levels within the band gap, which is not possible for periodic crystals at long, medium, and short ranges.

In this work, it was considered that the $\mathrm{TiO}_{2}$ lattice contained $\left[\mathrm{TiO}_{6}\right]^{x}-\left[\mathrm{TiO}_{5} \mathrm{~V}_{\mathrm{O}}{ }^{z}\right]$ clusters $\left(\mathrm{V}_{\mathrm{O}}{ }^{z}\right.$ is $\mathrm{V}_{\mathrm{O}}{ }^{o}, \mathrm{~V}_{\mathrm{O}}{ }^{\bullet}$, or $\left.\mathrm{V}_{\mathrm{O}}{ }^{\bullet \bullet}\right)$ as extrinsic defects, and these are linked to orderdisorder effects in the electronic structure. These defects create additional energy levels above the conduction band and below the valence band (Figures 4 and 5), thus decreasing the band gap. The effects can be considered in terms of the following reactions:

$$
\begin{aligned}
& {\left[\mathrm{TiO}_{6}\right]^{x}-\left[\mathrm{TiO}_{5} \mathrm{~V}_{\mathrm{O}}{ }^{x}\right] \longrightarrow\left[\mathrm{TiO}_{6}\right]^{\prime}-\left[\mathrm{TiO}_{5} \mathrm{~V}_{\mathrm{O}} \cdot\right]} \\
& {\left[\mathrm{TiO}_{6}\right]^{\prime}-\left[\mathrm{TiO}_{5} \mathrm{~V}_{\mathrm{O}}^{\cdot}\right]+\mathrm{H}_{2} \mathrm{O}+h \nu} \\
& \longrightarrow\left[\mathrm{TiO}_{6}\right]^{\prime}-\left[\mathrm{TiO}_{5} \mathrm{~V}_{\mathrm{O}}^{x}\right] \cdots \mathrm{OH}^{*}+\mathrm{H}^{\bullet} \\
& {\left[\mathrm{TiO}_{6}\right]^{\prime}-\left[\mathrm{TiO}_{5} \mathrm{~V}_{\mathrm{O}}^{\cdot}\right]+\mathrm{O}_{2}+h v} \\
& \longrightarrow\left[\mathrm{TiO}_{6}\right]^{x}-\left[\mathrm{TiO}_{5} \mathrm{~V}_{\mathrm{O}}^{\cdot}\right] \cdots \mathrm{O}_{2}^{\prime} \\
& {\left[\mathrm{TiO}_{6}\right]^{x}-\left[\mathrm{TiO}_{5} \mathrm{~V}_{\mathrm{O}}^{\cdot}\right] \cdots \mathrm{O}_{2}{ }^{\prime}+\mathrm{H}^{\bullet}} \\
& \longrightarrow\left[\mathrm{TiO}_{6}\right]^{x}-\left[\mathrm{TiO}_{5} \mathrm{~V}_{\mathrm{O}}^{\bullet}\right]+\mathrm{O}_{2} \mathrm{H}^{*}
\end{aligned}
$$

As expected, for UV illumination, $\mathrm{OH}$ radical generation is superior to that in visible illumination and a linear behavior for $\mathrm{OH}$ production is observed for all samples, indicating that nitrogen doping process changed radicals generation (Figure 9), though the role of $\mathrm{N}$ content is not totally clear yet. Even in higher contents (SAM 03), the $\mathrm{OH}$ radicals generation did not significantly modify with $\mathrm{N}$ amount in $\mathrm{TiO}_{2}: \mathrm{N}$. However, the photocatalytic activity did not present a clearly relation with $\mathrm{OH}$ radical generation proposed by this method. On the other hand, other radicals may be involved in Rhod-B degradation, as $\mathrm{O}_{2} \mathrm{H}$ radical and even for directly 
oxidation. Another cause for the increase in photocatalytic activity under UVC illumination of doped samples and not under visible is due to recombination charges induced for decrease in band gap value. In this case, there is not sufficient time to produce $\mathrm{OH}$ radical under visible illumination in doped samples as Figure 8 shows. Further studies are in progress to better describe the entire mechanism degradation of organic compound after doping process.

\section{Conclusion}

The results presented here conclude that the doping process create defects, especially oxygen vacancies $\left(\mathrm{V}_{\mathrm{O}}\right)$ in $\mathrm{TiO}_{2}$ lattice, which did not influence $\mathrm{OH}$ radical production when photocatalyst was illuminated, neither by UV or by visible radiation. In this scenario, probably does not occur $\mathrm{OH}$ radicals production alteration; however, the photocatalyst activity under visible illumination could be associated with the defects, confirmed by photoluminescence results. Another important effect presented in photocatalytic activity for doped samples is probably a charge recombination, induced by reduced band gap values. Then, the efficiency of Rhod$\mathrm{B}$ degradation process is reduced under visible illumination. The $\mathrm{TiO}_{2}: \mathrm{N}$ nanoparticles present photocatalytic activity under UVC illumination for other organic molecules such as $\mathrm{MO}$ and $\mathrm{MB}$ dyes. The powders synthetized present useful paper in solar cells and water splitting processes as the PL emission continuous could increase the efficiency of both systems as for photocatalytic processes.

\section{Conflict of Interests}

The authors declare that there is no conflict of interests regarding the publication of this paper.

\section{Acknowledgments}

The authors appreciate the financial support from CNPq (151177/2013-9), CAPES, FINEP, and EMBRAPA Instrumentação.

\section{References}

[1] R. L. Ziolli and W. F. Jardim, "Mechanism reactions of photodegradation of organic compounds catalyzed by $\mathrm{TiO}_{2}$," Quimica Nova, vol. 21, no. 3, pp. 319-325, 1998.

[2] R. Beranek, B. Neumann, S. Sakthivel et al., "Exploring the electronic structure of nitrogen-modified $\mathrm{TiO}_{2}$ photocatalysts through photocurrent and surface photovoltage studies," Chemical Physics, vol. 339, no. 1-3, pp. 11-19, 2007.

[3] R. Beranek and H. Kisch, "Tuning the optical and photoelectrochemical properties of surface-modified $\mathrm{TiO}_{2}$," Photochemical \& Photobiological Sciences, vol. 7, no. 1, pp. 40-48, 2008.

[4] J. L. Gole, J. D. Stout, C. Burda, Y. Lou, and X. Chen, "Highly efficient formation of visible light tunable $\mathrm{TiO}_{2-x} \mathrm{~N}_{x}$ photocatalysts and their transformation at the nanoscale," Journal of Physical Chemistry B, vol. 108, no. 4, pp. 1230-1240, 2004.
[5] W. Low and V. Boonamnuayvitaya, "A study of photocatalytic graphene- $\mathrm{TiO}_{2}$ synthesis via peroxo titanic acid refluxed sol," Materials Research Bulletin, vol. 48, no. 8, pp. 2809-2816, 2013.

[6] S. Sakthivel, M. Janczarek, and H. Kisch, "Visible light activity and photoelectrochemical properties of nitrogen-doped $\mathrm{TiO}_{2}$," The Journal of Physical Chemistry B, vol. 108, no. 50, pp. 1938419387, 2004.

[7] G. B. Soares, B. Bravin, C. M. P. Vaz, and C. Ribeiro, "Facile synthesis of $\mathrm{N}$-doped $\mathrm{TiO}_{2}$ nanoparticles by a modified polymeric precursor method and its photocatalytic properties," Applied Catalysis B: Environmental, vol. 106, no. 3-4, pp. 287-294, 2011.

[8] J. Zhang, Y. Wang, Z. Jin, Z. Wu, and Z. Zhang, "Visible-light photocatalytic behavior of two different $\mathrm{N}$-doped $\mathrm{TiO}_{2}$," Applied Surface Science, vol. 254, no. 15, pp. 4462-4466, 2008.

[9] H. Irie, Y. Watanabe, and K. Hashimoto, "Nitrogen-concentration dependence on photocatalytic activity of $\mathrm{TiO}_{2-x} \mathrm{~N}_{x}$ powders," Journal of Physical Chemistry B, vol. 107, no. 23, pp. 5483-5486, 2003.

[10] A. S. H. Lee, K. Li, Y.-W. Zhang, Z.-D. Sha, and H. Pan, "Ab initio study on the effects of dopant-defect cluster on the electronic properties of $\mathrm{TiO}_{2}$-based photocatalysts," International Journal of Hydrogen Energy, vol. 39, no. 5, pp. 2049-2055, 2014.

[11] B. D. Cullity and S. R. Stock, Elements of X-Ray Diffraction, Prentice Hall, Englewood Cliffs, NJ, USA, 3rd edition, 2011.

[12] J. Cao, B. Luo, H. Lin, B. Xu, and S. Chen, "Thermodecomposition synthesis of $\mathrm{WO}_{3} / \mathrm{H}_{2} \mathrm{WO}_{4}$ heterostructures with enhanced visible light photocatalytic properties," Applied Catalysis B: Environmental, vol. 111-112, pp. 288-296, 2012.

[13] C. W. Raubach, A. F. Gouveia, Y. V. B. de Santana et al., "Towards controlled synthesis and better understanding of blue shift of the CaS crystals," Journal of Materials Chemistry C, vol. 2, no. 15, pp. 2743-2750, 2014.

[14] W. Low and V. Boonamnuayvitaya, "Enhancing the photocatalytic activity of $\mathrm{TiO}_{2}$ co-doping of graphene- $\mathrm{Fe}^{3+}$ ions for formaldehyde removal," Journal of Environmental Management, vol. 127, pp. 142-149, 2013.

[15] B. Liu, X. Zhao, and L. Wen, "The structural and photoluminescence studies related to the surface of the $\mathrm{TiO}_{2}$ sol prepared by wet chemical method," Materials Science and Engineering B: Solid-State Materials for Advanced Technology, vol. 134, no. 1, pp. 27-31, 2006.

[16] G. L. Praveen, G. M. Lekha, V. M. Visakh, L. R. Reshma, and S. George, "Lanthanide magneto-luminescent and plasmonic $\left(\mathrm{Gd}_{2} \mathrm{O}_{3}: \mathrm{Eu} @ A u N R\right)$ nanoassembly for the turn-on fluorescence detection of nitro aromatic compound," Journal of Nanoparticle Research, vol. 16, no. 8, 2014.

[17] N. R. Yogamalar, M. Ashok, and A. C. Bose, "Blue emission and bandgap modification in $\mathrm{N}: \mathrm{ZnO}$ Nanorods," Functional Materials Letters, vol. 4, no. 3, pp. 271-275, 2011.

[18] F. H. Hussein, "Photochemical treatments of textile industries wastewater," in Advances in Treating Textile Effluent, chapter 6, InTech, Rijeka, Croatia, 2011.

[19] K. Dai, H. Chen, T. Peng, D. Ke, and H. Yi, "The degradation mechanism of methyl orange under photo-catalysis of $\mathrm{TiO}_{2}$ with mesoporous titania nanoparticles," Chemosphere, vol. 69, pp. 1361-1367, 2007.

[20] A. Houas, H. Lachheb, M. Ksibi, E. Elaloui, C. Guillard, and J. M. Herrmann, "Photocatalytic degradation pathway of methylene blue in water," Applied Catalysis B: Environmental, vol. 31, no. 2, pp. 145-157, 2001. 
[21] M. A. Lazar, S. Varghese, and S. S. Nair, "Photocatalytic water treatment by titanium dioxide: recent updates," Catalysts, vol. 2 , no. 4, pp. 572-601, 2012.

[22] J.-Y. Li, W.-H. Ma, P.-X. Lei, and J.-C. Zhao, "Detection of intermediates in the $\mathrm{TiO}_{2}$-assisted photodegradation of Rhodamine B under visible light irradiation," Journal of Environmental Sciences, vol. 19, no. 7, pp. 892-896, 2007.

[23] K.-I. Ishibashi, A. Fujishima, T. Watanabe, and K. Hashimoto, "Quantum yields of active oxidative species formed on $\mathrm{TiO}_{2}$ photocatalyst," Journal of Photochemistry and Photobiology A: Chemistry, vol. 134, no. 1-2, pp. 139-142, 2000.

[24] L. S. Cavalcante, J. C. Sczancoski, N. C. Batista, E. Longo, J. A. Varela, and M. O. Orlandi, "Growth mechanism and photocatalytic properties of $\mathrm{SrWO}_{4}$ microcrystals synthesized by injection of ions into a hot aqueous solution," Advanced Powder Technology, vol. 24, no. 1, pp. 344-353, 2013. 

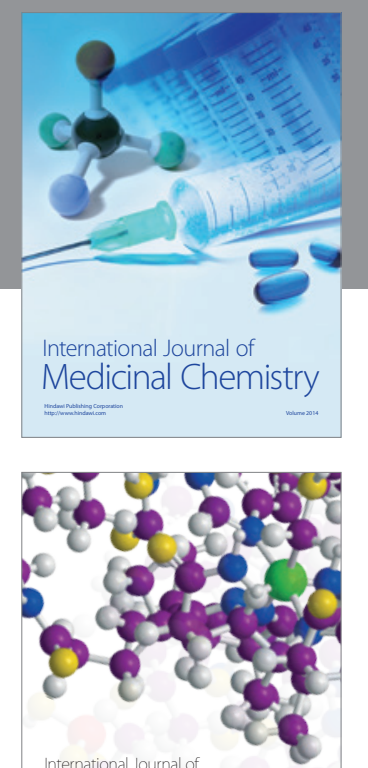

\section{Carbohydrate} Chemistry

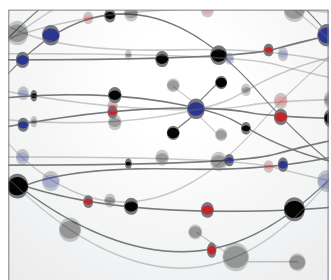

The Scientific World Journal
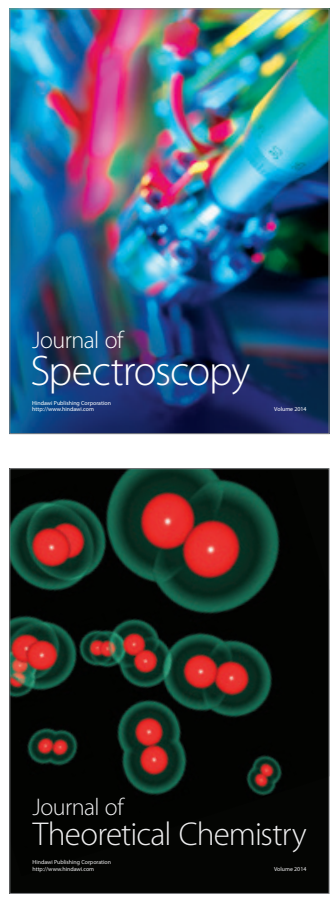
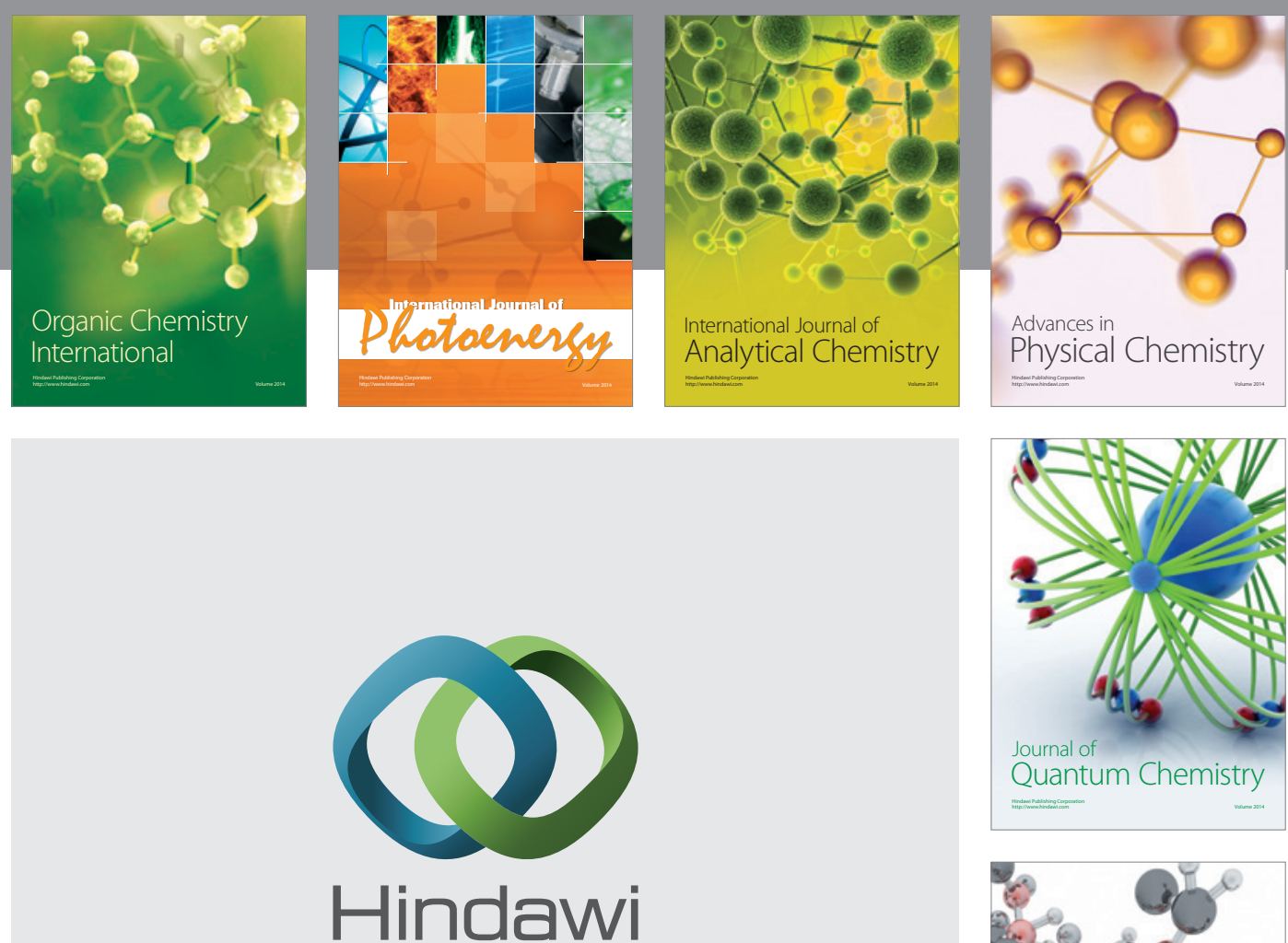

Submit your manuscripts at

http://www.hindawi.com

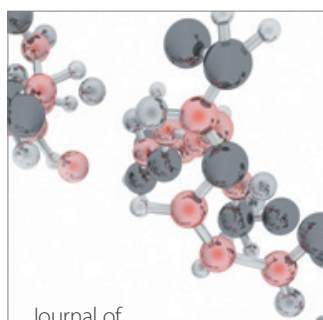

Analytical Methods

in Chemistry

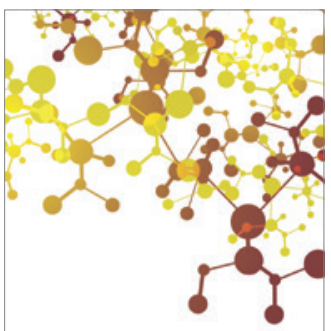

Journal of

Applied Chemistry

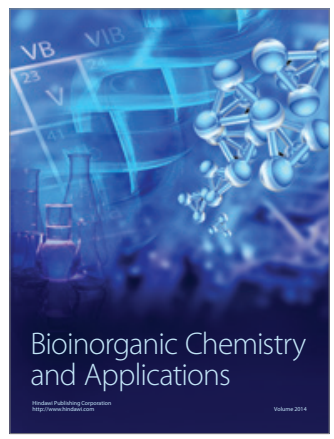

Inorganic Chemistry
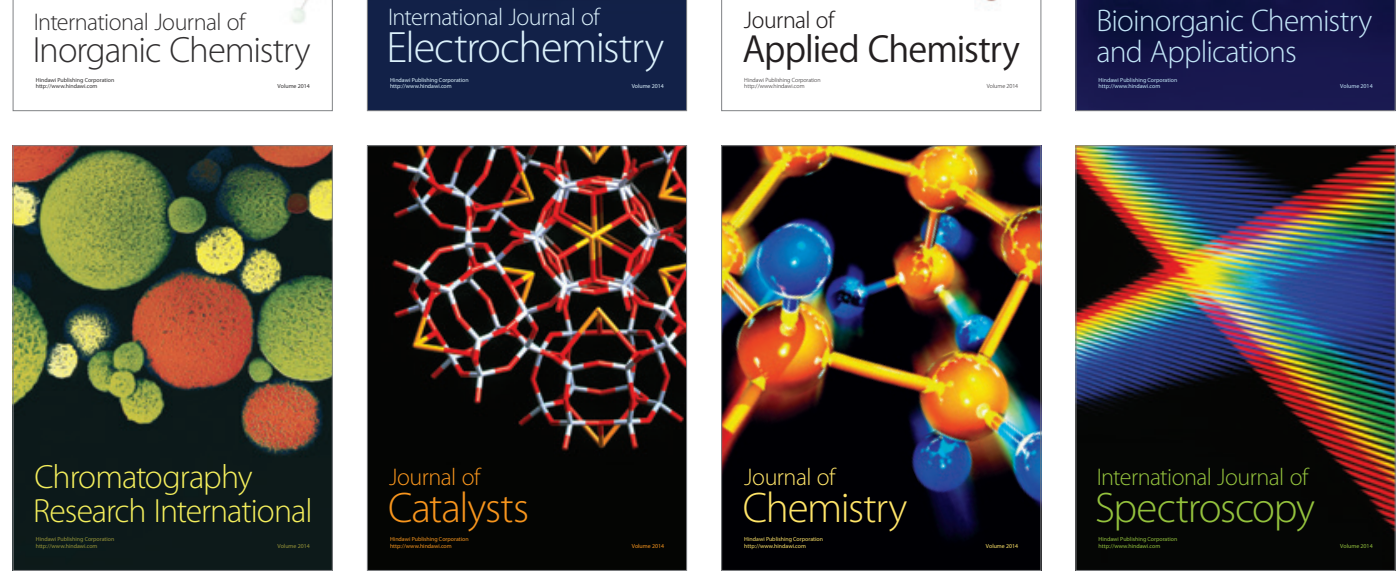